УдК 316.356.2-053.81(47+57)

\title{
ЖИЗНЕННЫЙ МИР МОЛОДОЙ СЕМЬИ В РОССИИ: МЕТОДОЛОГИЧЕСКИЙ КОНСТРУКТ СОЦИОЛОГИЧЕСКОГО ИССЛЕДОВАНИЯ
}

\author{
Артамонова Яна Викторовна, \\ janaserduchenko@mail.ru \\ Южный федеральный университет, \\ Россия, 344006, г. Ростов-на-Дону, ул. Пушкинская, 160
}

Артамонова Яна Викторовна, кандидат социологических наук, старший преподаватель кафедры региональной социологии и моделирования социальных процессов Института социологии и регионоведения Южного федерального университета.

В рамках статьи автор обращается к теоретико-методологическим основам исследования молодой семьи. Автор отмечает, что изучение молодой семьи является популярной отраслью социологии с различной методологией социологического познания, куда можно отнести структурнофункциональный подход, консервативно-кризисный, либерально-прогрессистский теоретикометодологические подходы, концепцию модернизации семьи, теорию обмена, социальнопсихологическую теорию, а также концепцию семейного жизненного пути, феноменологическую теорию. По мнению автора статьи, для более глубокой социологической рефлексии жизнедеятельности молодой семьи необходимо обратиться к ее жизненному миру, для рассмотрения которого необходимо разработать специальный методологический конструкт социологического изучения. В связи с этим цель работы - выявление теоретико-методологических оснований социологической рефлексии жизненного мира молодой семьи. В результате проведенного анализа автор приходит к выводу, что наиболее подходящий методологический конструкт изучения жизненного мира молодых супругов складывается на основе неоклассической модели научного исследования, которая базируется на идеях конструктивизма. Для наиболее глубокой рефлексии при рассмотрении жизненного мира автор предлагает использовать теоретическую концепцию социологии жизни и рискологическую концепцию молодежи, которая позволит найти болевые точки молодой семьи, нарушающие стабильное функционирование ее жизненного мира.

Ключевые слова: Социология семьи, семья, молодая семья, жизненный мир, ценности, ценностные установки, жизненный мир молодой семьи, методология, методологический конструкт.

\section{Введение}

Семья играет в жизни каждого человека огромную роль, которую невозможно переоценить: именно здесь формируются ценностные ориентации личности и создаются семейные традиции.

Трансформационные процессы, которые мы можем наблюдать в России в течение последних десятилетий, оказывают существенное воздействие на различные социальные институты, где институт семьи не является исключением. Особые изменения наблюдаются в социальном институте молодой семьи. Современные молодые семьи начинают свой жизненный путь в условиях особой рискогенной социальной реальности, которая, в свою очередь, влияет на распространение различного рода семейнобрачных практик. Осмысление процессов становления и развития молодой семьи делает данную проблематику весьма актуальной для современных научноисследовательских практик. 
Изучение института семьи является весьма популярной отраслью социологической науки. Особой актуальностью пользуются исследования, которые направлены на изучение молодой семьи. Данное обстоятельство связано с тем, что именно молодая семья выступает в качестве мощного ресурса, позволяющего осуществлять общественное развитие государства.

При исследовании института молодой семьи российские ученые опираются на огромный пласт теорий и концепций семьи, которые помогают выявить существующие проблемы и болевые точки молодых семей в России. Помимо исследований функционирования молодой семьи в российском обществе, когнитивный интерес современных социологов сосредотачивается на социальной реальности, выступающей как некое связующее звено между целой и отдельной категорией социального взаимодействия на микроуровне, что, в свою очередь, делает актуальной проблематику изучения жизненного мира.

В связи с постоянной трансформацией реальности происходит изменение и в жизнедеятельности молодых семей, которое выражается в распространении новых моделей семьи и трансформации семейных ценностей. Данная реакция не может не вызывать интерес со стороны ученых. Одним из способов исследования реакции молодых семей на трансформацию может являться обращение к их жизненному миру, что позволяет комплексно проанализировать макро- и микроаспекты жизни молодых супругов.

Таким образом, чтобы комплексным образом подойти к изучению проблем и болевых вопросов, волнующих многие российские молодые семьи, необходимо изучить жизненный мир российской молодой семьи, что, в свою очередь, требует разработки определенного методологического конструкта социологического изучения. Цель данной статьи выявить теоретико-методологические основания социологического анализа жизненного мира молодой семьи.

\section{Молодая семья: теоретико-методологические основы исследования в научном дискурсе}

Обращение к исследованиям института семьи показывает, что ученые используют огромное количество теоретических концепций для рассмотрения семейно-брачных отношений. В рамках данного раздела будут рассмотрены теоретико-методологические основы исследования молодой семьи в России.

Анализ научно-исследовательской литературы, направленной на изучение молодой семьи, показывает, что когнитивный интерес исследователей сосредоточен на таких направлениях, как добрачное поведение молодежи [1], мотивация вступления в семейно-брачные отношения [2], распределение ролей в молодой семье [3], функции молодой семьи [4], репродуктивное поведение молодых людей $[5,6]$, адаптационные практики молодых супругов [7], ценности молодой семьи [8]. Исходя из выбранного направления исследования, ученые опираются на определенные теоретические концепции семьи и брака, что позволяет им разработать методологический конструкт выбранного ими предмета исследования.

Методологический конструкт представляет собой модель социологического исследования, так называемый когнитивный аналог, который обладает типичными чертами научно-исследовательских практик в социологии [9].

При изучении молодой семьи исследователи прибегают к использованию различных методологических конструкций. Проведенный нами анализ позволяет выделить в отечественной социологической науке два основных направления в области семейной проблематики: консервативно-кризисный и либерально-прогрессистский (эволюционный) теоретико-методологические подходы. 
Использование консервативно-кризисного подхода позволяет объяснить дисфункции, происходящие в жизнедеятельности молодой семьи. На основе данного теоретико-методологического подхода фиксируется внутренняя динамика семейных отношений молодых супругов. В основе консервативно-кризисного подхода лежит структурный функционализм, на основании которого любая семья, в том числе и молодая, должна выполнять социально значимые функции, что определяет семью как стабильную ячейку социума. Основные идеи структурного функционализма описаны в трудах Г. Спенсера и Э. Дюркгейма [10]. Идеи Э. Дюркгейма, как и многих сторонников структурно-функциональной теории, заключаются в следующем: в каждой семье должно быть разделение ролей по полу, т. к. данное разделение поддержит существование индустриального общества. При реализации данной идеи муж в семье отвечает за реализацию инструментальных функций, а ответственность жены находится в зоне выполнения экспрессивной функции, что позволяет ей поддерживать уют в доме и заботиться о благополучии членов семьи. Иными словами, основная идея структурногофункционализма при исследовании семьи и брака заключается в рассмотрении стабильности семьи в качестве элемента социума, который функционально связан с обществом [11].

Также принцип структурного функционализма лежит в основе концепции модернизации семьи В. Гуда [12]. Данный исследователь полагал, что при формировании индустриального общества основой служит нуклеарная семья. Изменение структуры института молодой семьи означает и изменение его функций. При таком изменении социального института семьи осуществляется добровольный выбор молодого супруга, где не мнение окружающих людей, а любовь играет главную роль. В связи с такими функциональными изменениями возникает и обеспокоенность, что семейные структуры молодежи станут более дезорганизованными, что повлечет за собой увеличение конфликтов и рост разводов в молодых семьях, а значит, и кризиса социального института семьи не избежать.

При исследовании молодой семьи ученые часто прибегают к теории социального обмена и теории рационального выбора. Основой данных теорий является то, что они обращены конкретно к индивиду, поскольку именно индивид причастен к созданию социальной структуры. Семья же является совокупностью индивидов. Основываясь на данные теории, исследователи рассматривают индивидуальные мотивационные факторы молодых людей. Современные молодые люди часто рациональны и эгоистичны, а значит, они максимизируют своё благосостояние.

В связи с тем, что молодежь максимизирует свое благосостояние, многие исследователи при рассмотрении молодой семьи прибегают к использованию экономической теории Г. Беккера, которая идеологически заключается в том, что брачный выбор молодого человека является эффективным, если высококачественный мужчина в жены выбрал высококачественную женщину, а неэффективный брачный выбор заключается в том, что низкокачественные мужчины выбирают низкокачественных женщин. Иными словами, здесь мы наблюдаем принцип «качества» брачных партнеров, а эффективность брака - это его «продукция». В рамках экономической теории активно используется такое понятие, как брачный рынок, а сама семья рассматривается как домохозяйство. Репродуктивная функция молодой семьи при использовании экономической концепции Г. Беккера объясняется исследователями как приобретение «товаров длительного пользования».

Также не менее актуальной для рассмотрения современных семейных практик является социально-психологическая концепция, в рамках которой молодая семья высту- 
пает в качестве автономной подсистемы в цепочке «социум-семья-индивид», а также трансперсональной системой [13]. Другими словами, семья - это такая социальная группа, жизнедеятельность которой не может обходиться без конфликтов, что обуславливает обращение к подходу социального конфликта с позиций научной конфликтологической парадигмы. Возникновение конфликтов в молодой семье может выступать как следствие разных ресурсов у ее членов, т. е. в рамках конфликтологической концепции семья рассматривается учеными в качестве пространства различных противоречий.

Обращаясь к вопросу семейно-брачных отношений, мы видим, что семья и семейные проблемы молодых супругов обладают междисциплинарным характером. В связи с этим нельзя обойти стороной системный подход, в рамках которого под семьей понимают социальную систему, которая при взаимодействии с окружающей средой обладает свойством самоорганизации. При помощи системного подхода исследователи имеют возможность рассмотреть такие подсистемы, как супружеская, детскородительская, родительская и личностная. Гибкость подсистем семейной системы позволяет молодой семье оставаться долгое время единой системой.

Для рассмотрения молодой семьи некоторые исследователи применяют институциональный подход, который дает возможность исследовать семью как некую систему, которая обладает формальные нормами, а также имеет неформальные ограничения, позволяющие регулировать поведение молодых супругов [14].

При анализе таких предметных областей, как родительство в молодой семье, а также при рассмотрении отношений супругов в цепочке «семья-работа» фамилисты часто прибегают к гендерному подходу, который позволяет проследить роль мужчин и женщин в семейных практиках [15].

Не менее значимыми для современных исследовательских проектов являются такие теоретико-методологические подходы, как подход развития семейного жизненного пути и феноменологическая концепция. Обращаясь к подходу семейного жизненного пути, мы видим взаимосвязь с социально-психологическим подходом. Подход семейного жизненного пути базируется на трех составляющих его подходах: подход жизненного развития, подход жизненного пути, подход семейного развития. Данные подходы активно используются в рамках исследований жизненных стратегий молодой семьи и качества жизни молодых супругов.

Безусловно, нельзя не отметить тот факт, что жизненные семейные стадии имеют схожие черты на семейном жизненном пути различных семей, но в любом случае необходимо понимать, что каждая семья индивидуальна. Поэтому при исследовании семьи, в том числе и молодой, обладает актуальностью феноменологическая теория, которая была разработана А. Шюцом [16]. В рамках данной концепции подчеркивается, что собственную жизнь каждая семья понимает по-своему. Исследователи, которые при изучении молодой семьи опираются на идеи данного подхода, полагают, что слияние двух индивидов происходит не только для совместного проживания, но и для того, чтобы у членов семьи появился общий взгляд на мир. Ведь в процессе «биографического слияния» супругов происходит не только усвоение опыта супругами, но и разделение супругами общего способа типизации и объяснения этого опыта. Таким образом, с феноменологической точки зрения семья изучается посредством исследования смыслов межличностных семейных отношений. Феноменологический подход относится к группе теорий интерпретации человеческого поведения и позволяет проследить повседневные практики семейного образа жизни [17]. 


\section{Жизненный мир молодой семьи: методологические ориентиры социологического исследования}

Для того чтобы провести анализ жизненного мира молодой семьи в современном российском обществе и выявить его особенности, необходимо разработать методологическое пространство изучения жизненного мира молодой семьи. Методологическое пространство выступит каркасом исследования, при помощи которого возможно будет изучить акторов жизненного мира - молодых супругов.

При разработке методологического конструкта важно определиться с ключевыми понятия исследования - молодая семья и жизненный мир.

Следует отметить, что к настоящему времени среди фамилистов не сложилось единого мнения в вопросе определения дефиниции «молодая семья».

При определении дефиниции «молодая семья» важно фиксировать общую картину функционирования молодой семьи, а не только ее начальный этап, также необходимо учесть современные тенденции развития семьи и общества в целом. Если учитывать данные показатели, то для определения молодой семьи лучше применять интегративный подход [18]. Опираясь на интегративный подход, под молодой семьей подразумевается «союз молодых людей (мужчины и женщины) в возрасте до 35 лет, на основе супружества, родительства, каждый представитель которого идентифицирует себя с членами этого союза, разделяя ответственность за его существование и жизнедеятельность» [19].

При создании семьи важным аспектом является формирование единого образа семьи среди молодых супругов. На основе данного образа будут реализовываться функции семьи, которые находят свое отражение в ценностных ориентациях, а затем и в социальном поведении молодой семьи. Для понимания структуры ценностных ориентаций и поведенческих практик молодой семьи следует обратиться к концепции социологии жизни, разработанной Ж.Т. Тощенко [20-22]. В основе данной концепции лежит дефиниция «жизненный мир», обладающая по мнению Ж.Т. Тощенко следующей структурой: общественное сознание, поведение (деятельность), среда обитания человека [22].

Для того чтобы провести анализ жизненного мира любого объекта исследования, необходимо рассмотреть такие компоненты, как сознание, поведение, социальная среда, которые эмпирически измеряются через знание, мнение, потребности, мотивы, интересы, ценностные ориентации и установки, поступок, действие, виды поведения, макросреда, мезосреда, микросреда, социальная инфраструктура [21].

Жизненный мир - это среда, необходимая молодой семье для взаимодействия супругов в процессе решения возникающих проблем. На основе концепции социологии жизни можно выделить структуру жизненного мира молодой семьи. Компоненты структуры выстраиваются на основе показателей молодой семьи и описанных компонентов жизненного мира (рис. 1).

В процессе социальной коммуникации акторы (молодые супруги) осуществляют совместную деятельность, направленную на удовлетворение потребностей семьи. В качестве второго элемента выступают внешние факторы социальной среды, которые оказывают существенное влияние на ценностные ориентации и установки супругов. Ценностные ориентации и установки являются для молодой семьи неким ориентиром, способствующим сформировать правильный образ семьи, а также реализовывать семейные практики. Также в рамках второго элемента жизненного мира можно отметить и внутренние факторы, куда можно отнести мотивы создания семьи. Семейные практики молодых супругов выстраиваются на основе сложившихся ценностных ориентаций и установок. 


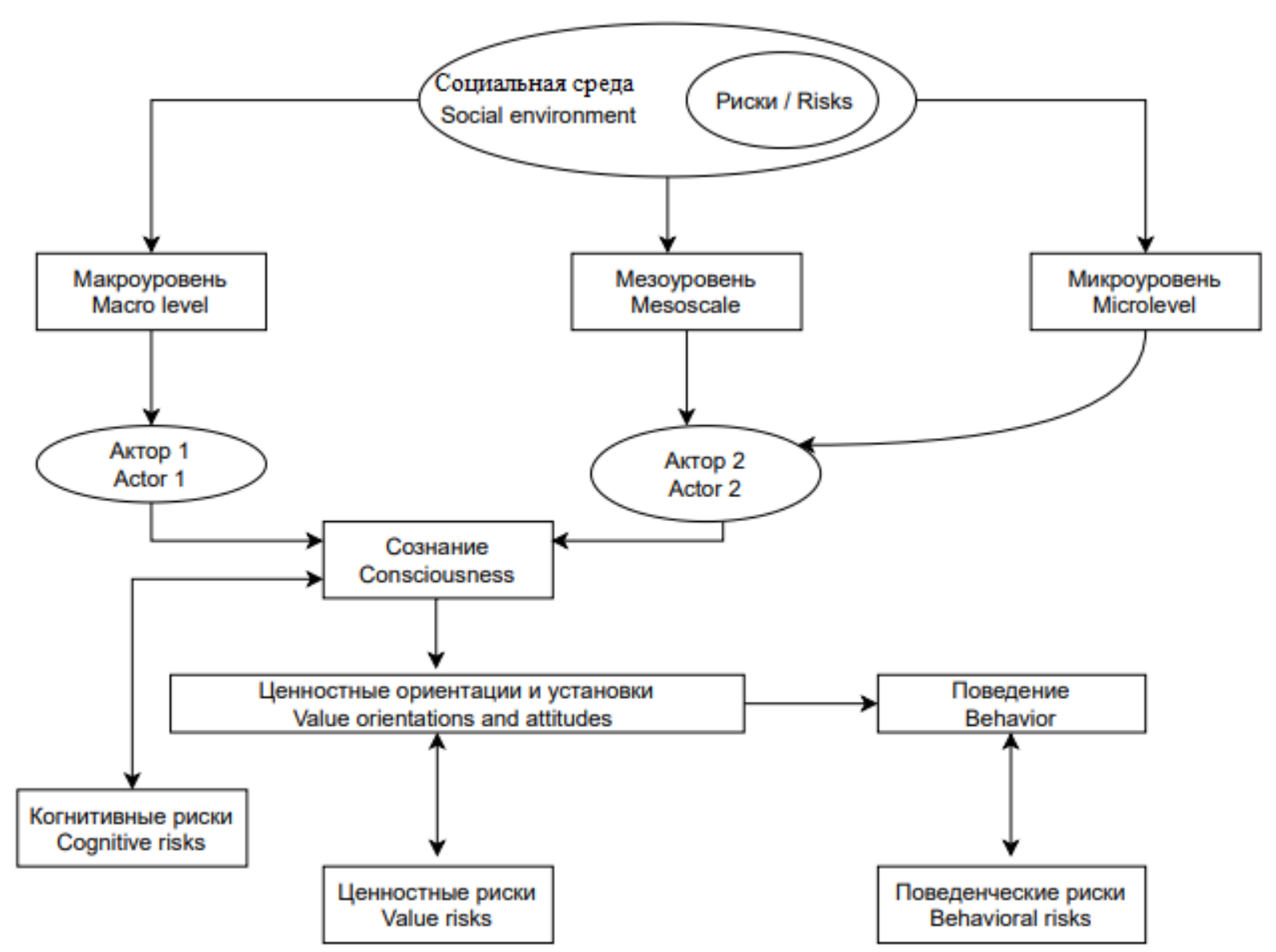

Puc. 1. Структура жизненного мира молодой семьи

Fig. 1. Structure of the life world of a young family

Исследование жизненного мира нельзя провести без обращения к социальной среде. При конструировании жизненного мира огромную роль играют внешние факторы социальной среды: совокупность экономических, политических, социальных условий. В России активно происходят социально-экономические и социальнополитические изменения, что влияет на трансформацию пространства жизненного мира молодой семьи. Данные изменения становятся неким триггером, который может поспособствовать нестабильности жизнедеятельности молодых супругов. Исходя из этого, при построении методологического конструкта для исследования жизненного мира молодой семьи стоит обратиться к рискологической концепции в молодежной среде, разработанной Ю.А. Зубок и В.И Чупровым [23]. На основе данной концепции можно рассмотреть риски разрушения жизненного мира молодой семьи.

Внешние и внутренние факторы социальной среды оказывают существенное влияние на формирование жизненного мира супругов. На микроуровне проводится рассмотрение того, как внешние факторы социальной среды воспринимаются молодыми супругами.

Любой выстроенный методологический конструкт необходим для эмпирического изучения предмета исследования. В связи с этим предложенный в данном разделе методологический конструкт позволяет провести эмпирического измерение жизненного мира молодой семьи при помощи трехкомпонентной методики измерения (рис. 2). 


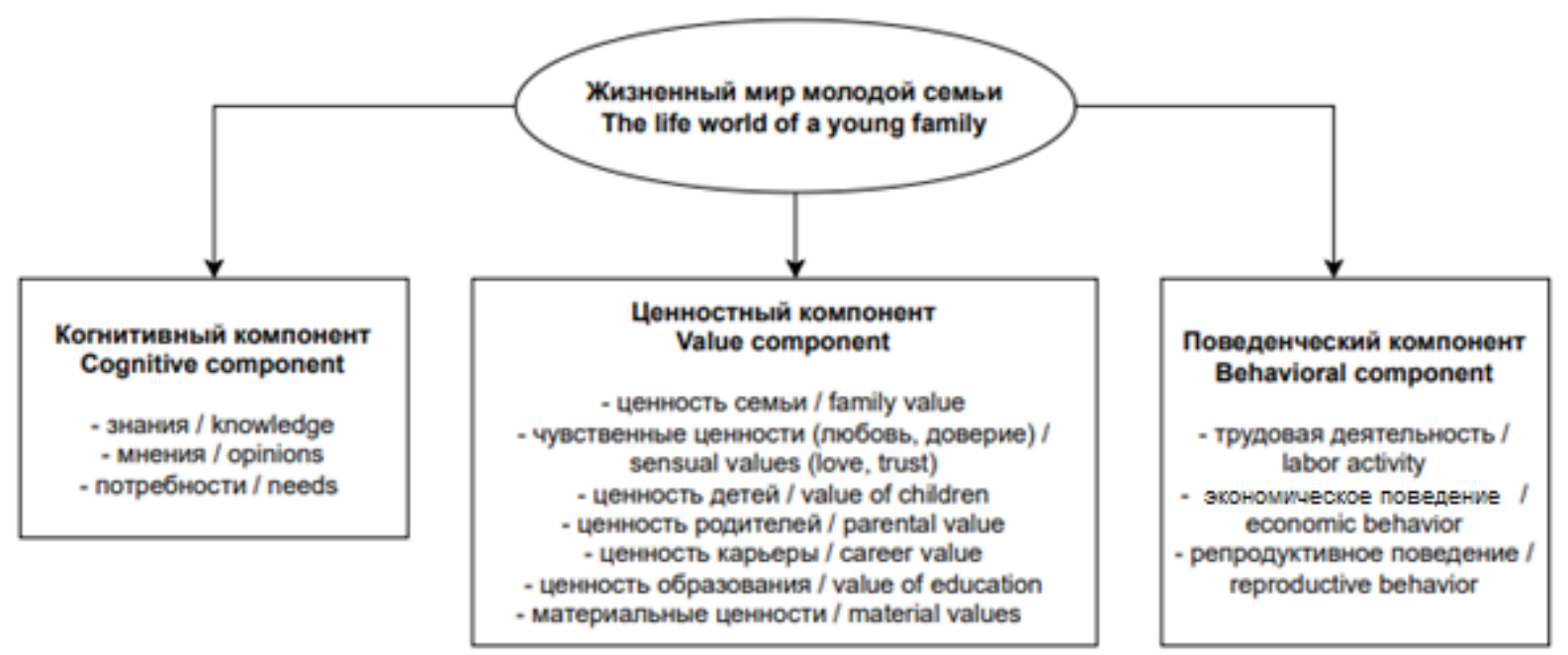

Puc. 2. Структура измерения жизненного мира молодой семьи

Fig. 2. Structure of the measurement of the life world of a young family

\section{Заключение}

Молодая семья очень часто становится объектом современных исследований. В зависимости от выбранных направлений предметного поля исследования ученые прибегают к тем или иным методологическим основаниям: структурнофункциональный подход, консервативно-кризисный, либерально-прогрессистский и теоретико-методологические подходы, концепцию модернизации семьи, теорию обмена, социально-психологическую теорию, а также концепцию семейного жизненного пути, феноменологическую теорию.

Для наиболее глубокой социологической рефлексии жизнедеятельности молодой семьи и используемых семейных практик молодых супругов важно применять комплексный анализ. В связи с этим при построении методологического конструкта исследования жизненного мира молодой семьи применяется неоклассическая модель, которая базируется на идеях конструктивизма. Для решения научно-исследовательских задач при изучении жизненного мира используется теоретическая концепция социологии жизни и рискологической концепции в молодежной среде. При исследовании факторов внешней среды целесообразно обращаться к структурно-функциональному подходу, а рассмотрение внутренних факторов происходит на основе феноменологического подхода.

Таким образом, проведенный в рамках данной работы анализ теоретикометодологической базы исследования жизненного мира молодой семьи и выстроенный методологический конструкт позволяет глубже понять специфику жизни молодых супругов, исследовать их когнитивные и ценностные механизмы, разобраться в многообразии проблем, с которыми сталкиваются молодые семьи. Концепция измерения жизненного мира молодой семьи позволяет исследователю детально рассмотреть такие элементы жизнедеятельности молодой семьи, как мотивы, потребности, интересы, ценностные ориентации, установки и поведенческие компоненты (действия, поступки).

\section{СПИСОК ЛИТЕРАТУРЫ}

1. Яковлев Л.С., Кучеренко В.С. Гендерные различия стратегий добрачного поведения молодежи // Актуальные проблемы экономики и менеджмента. - 2015. - № 2 (6). - С. 114-119.

2. Пучкова Л.Л. Мотивация вступления в брак молодежи на примере студентов-психологов: гендерный аспект // Ученые записки Крымского федерального университета имени В.И. Вернадского. Социология. Педагогика. Психология. - 2015. - Т. 1 (67). - № 4. - С. 195-203. 
3. Евграфова Ю.А. Ролевая структура в молодой супружеской паре // Вестник Санкт-Петербургского университета. Психология. - 2019. - Т. 9. - № 4. - С. 411-423.

4. Жданова М.А, Трубицына Л.В. Субъективные представления молодых людей, находящихся в браке, о функциях современной семьи // Вестник Владимирского государственного университета им. Александра Григорьевича и Николая Григорьевича Столетовых. Серия «Педагогические и психологические науки». - 2020. - № 43 (62). - С. 126-134.

5. Попова Л.А., Шишкина М.А. Брачно-семейные и репродуктивные установки современной молодежи // Проблемы развития территории. - 2016. - № 5 (85). - С. 57-71.

6. Хайруллин Р.Р., Соловьев М.М. Факторы репродуктивного поведения молодой семьи: православные ценности // Вестник экономики, права и социологии. - 2015. - № 2. - С. 222-224.

7. Кикоть А.С. Микросоциальные факторы влияния на социальную адаптацию молодой семьи в российском обществе // Гуманитарные, социально-экономические и общественные науки. - 2018. № 2. - C. 40-44.

8. Сидорова Н.П. Брак, семья и дети в сознании молодежи: социологический анализ // Власть и управление на Востоке России. - 2017. - № 3 (80). - С. 105-110.

9. Лубский А.В. Методология региональных исследований. - М.: Инфра-М, 2019. - 223 с.

10. Дюркгейм Э. О разделении общественного труда. Метод в социологии. - М.: Наука, 1991. -572 с.

11. Гурко Т.А. Теоретические подходы к изучению трансформации института семьи // Социологический журнал. - 2020. - № 1. - С. 31-54.

12. Good W. World revolution and family patterns. - New York: Free Press, 1963. - 432 p.

13. Орлов А.Б. Эволюция межличностных отношений в семье: основные подходы, ориентации и тенденции // Журнал практического психолога. - 2005. - № 4. - С. 174-190.

14. Ростовская Т.К. Развитие института молодой семьи в современном обществе // Государственный советник. - 2013. - № 2 (2). - С. 46-52.

15. Силласте Г.Г. От решения женского вопроса к новому гендерному порядку: движение в модусах социального времени // Гуманитарий Юга России. - 2017. - Т. 6. - № 5. - С. 48-62.

16. Шюц А. Избранное: мир, светящийся смыслом. - М.: РОССПЭН, 2004. - 1056 с.

17. Риббенс Маккарти Дж., Эдвардс Р. Исследования семьи: основные понятия - М.: ИД Высшей школы экономики, 2018. - 343 с.

18. Верещагина А.В. Трансформация института семьи и демографические процессы в российском обществе: дис. ... д-ра социол. наук. - Ростов-на-Дону, 2009. - 419 с.

19. Сердюченко Я.В. Жизненный мир молодой семьи: особенности формирования и риски разрушения (на материалах ростовской области): автореф. дис. ... канд. соц. наук. - Ростов-на-Дону, 2018. - 38 с.

20. Тощенко Ж.Т. Жизненный мир - методологическая характеристика социологии жизни // Вестник РГГУ. Серия «Философия. Социология. Искусствоведение». - 2015. - № 7. - С. 9-14.

21. Тощенко Ж.Т. Социология жизни. - М.: ЮНИТИ-ДАНА, 2016. - 399 с.

22. Тощенко Ж.Т. Социология жизни как теоретическая концепция // Социологические исследования. 2015. - № 1. - С. 106-116.

23. Чупров В.И., Зубок Ю.А., Уильямс К. Молодежь в обществе риска. - М.: Наука, 2001. - 229 с.

Поступила 24.04.2021 2. 
UDC 316.356.2-053.81(47+57)

\title{
LIFE WORLD OF A YOUNG FAMILY IN RUSSIA: A METHODOLOGICAL CONSTRUCT OF A SOCIOLOGICAL STUDY
}

\author{
Yana V. Artamonova, \\ janaserduchenko@mail.ru \\ Southern Federal University, \\ 160, Pushkinsky avenue, Rostov-on-Don, 344006, Russia
}

Yana V. Artamonova, Cand. Sc., senior lecturer, Southern Federal University.

Within the framework of this article, the author turns to the theoretical and methodological foundations of the study of a young family. The author notes that the study of a young family is a popular branch of sociology with different methodology of sociological cognition, which can include the structural-functional approach, conservative-crisis, liberal-progressive theoretical and methodological approaches, the concept of family modernization, exchange theory, socio-psychological theory, and the concept of family life path, phenomenological theory as well. According to the author of the article, for a deeper sociological reflection on the life of a young family, it is necessary to turn to its life world. In order to consider the life world of young spouses, it is necessary to develop a special methodological construct of sociological study. In this regard, the purpose of this work is to identify the theoretical and methodological foundations of sociological reflection of the life world of a young family. As a result of the analysis, the author comes to the conclusion that the most appropriate methodological construct for studying the life world of young spouses is formed on the basis of a neoclassical model of scientific research, which is based on the ideas of constructivism. For the deepest reflection when considering the life world, the author proposes to use the theoretical concept of the sociology of life; it will also be appropriate to use the riskological concept of youth, which will allow finding pain points of a young family that disrupt the stable functioning of its life world.

Key words: Sociology of the family, family, young family, life world, values, value attitudes, life world of a young family, methodology, methodological construct.

\section{REFERENCES}

1. Yakovlev L.S., Kucherenko V.S. Gendernye razlichiya strategiy dobrachnogo povedeniya molodezhi [Gender differences in strategies for premarital behavior of young people]. Aktualnye problemy ekonomiki $i$ menedzhmenta, 2015, no. 2 (6), pp. 114-119.

2. Puchkova L.L. Motivatsiya vstupleniya $\mathrm{v}$ brak molodezhi na primere studentov-psikhologov: genderny aspekt [Motivation for marriage of young people on the example of psychology students: the gender aspect]. Uchenye zapiski Krymskogo federalnogo universiteta imeni V.I. Vernadskogo. Sotsiologiya. Pedagogika. Psikhologiya, 2015, no. 4, pp. 195-203.

3. Evgrafova Yu.A. Rolevaya struktura v molodoy supruzheskoy pare [Role structure in a young married couple]. Vestnik Sankt-Peterburgskogo universiteta. Psikhologiya, 2019, no. 4, pp. 411-423.

4. Zhdanova M.A., Trubitsyna L.V. Subektivnye predstavleniya molodykh lyudey, nakhodyashchikhsya v brake, o funktsiyakh sovremennoy semyi [Subjective ideas of married young people about the functions of a modern family]. Vestnik Vladimirskogo gosudarstvennogo universiteta im. Aleksandra Grigorevicha i Nikolaya Grigorevicha Stoletovykh. Seriya «Pedagogicheskie i psikhologicheskie nauki», 2020, no. 43 (62), pp. 126-134.

5. Popova L.A., Shishkina M.A. Brachno-semeynye i reproduktivnye ustanovki sovremennoy molodezhi [Marriage and family and reproductive attitudes of modern youth]. Problemy razvitiya territorii, 2016, no. 5 (85), pp. 57-71. 
6. Khairullin R.R., Soloviev M.M. Faktory reproduktivnogo povedeniya molodoy semi: pravoslavnye tsennosti [Factors of reproductive behavior of a young family: Orthodox values]. Vestnik ekonomiki, prava $i$ sotsiologii, 2015, no. 2, pp. 222-224.

7. Kikot A.S. Mikrosotsialnye faktory vliyaniya na sotsialnuyu adaptatsiyu molodoy semi v rossiyskom obshchestve [Microsocial factors of influence on the social adaptation of a young family in Russian society]. Gumanitarnye, sotsialno-ekonomicheskie i obshchestvennye nauki, 2018, no. 2, pp. 40-44.

8. Sidorova N.P. Brak, semya i deti v soznanii molodezhi: sotsiologicheskiy analiz [Marriage, family and children in the minds of young people: a sociological analysis]. Vlast i upravlenie na Vostoke Rossii, 2017, no. 3 (80), pp. 105-110.

9. Lubsky A.V. Metodologiya regionalnykh issledovaniy [Regional study's methodology]. Moscow, Infra-M Publ., 2019. 223 p.

10. Durkheym E. O razdelenii obshchestvennogo truda. Metod v sotsiologii [On the division of social labor. Method in Sociology]. Moscow, Nauka Publ., 1991. 572 p.

11. Gurko T.A. Teoreticheskie podkhody k izucheniyu transformatsii instituta semi [Theoretical approaches to studying the transformation of the family institution]. Sotsiologicheskiy zhurnal, 2020, no. 1, pp. 31-54.

12. Good W. World revolution and family patterns. New York, Free Press, 1963. 432 p.

13. Orlov A.B. Evolyutsiya mezhlichnostnykh otnosheniy v seme: osnovnye podkhody, orientatsii i tendentsii [Evolution of interpersonal relations in the family: basic approaches, orientations and trends]. Zhurnal prakticheskogo psikhologa, 2005, no. 4, pp. 174-190.

14. Rostovskaya T.K. Razvitie instituta molodoy semyi v sovremennom obshchestve [Development of the institution of a young family in modern society]. Gosudarstvenny sovetnik, 2013, no. 2 (2), pp. 46-52.

15. Sillaste G.G. Ot resheniya zhenskogo voprosa k novomu gendernomu poryadku: dvizhenie v modusakh sotsialnogo vremeni [From the solution of the women's question to the new gender order: movement in the modes of social time]. Gumanitariy Yuga Rossii, 2017, vol. 6, no. 5, pp. 48-62.

16. Schyuts A. Izbrannoe: mir, svetyashchiysya smyslom [Favorites: a world glowing with meaning]. Moscow, ROSSPEN Publ., 2004. 1056 p.

17. Ribbens McCarthy J., Edwards R. Issledovaniya semi: osnovnye ponyatiya [Key concepts of family studies]. Moscow, Higher school of Economics Publ., 2018. 343 p.

18. Vereshchagina A.V. Transformatsiya instituta semyi $i$ demograficheskie protsessy $v$ rossiyskom obshchestve. Dis. Dokt. nauk [Transformation of the family institution and demographic processes in Russian society. Dr. Diss.]. Rostov-on-Don, 2009. 419 p.

19. Serdyuchenko Ya.V. Zhiznenny mir molodoy semi: osobennosti formirovaniya i riski razrusheniya (na materialakh Rostovskoy oblasti). Avtoreferat Dis. ... Kand. nauk [The life world of a young family: features of formation and risks of destruction (based on materials from the Rostov region): Cand. Diss. Abstract]. Rostov-on-Don, 2018. 38 p.

20. Toshchenko Zh.T. Zhiznenny mir - metodologicheskaya kharakteristika sotsiologii zhizni [The world of life - a methodological characteristic of the sociology of life]. Vestnik RGGU. Seriya «Filosofiya. Sotsiologiya. Iskusstvovedenie», 2015, no. 7, pp. 9-14.

21. Toshchenko Zh.T. Sotsiologiya zhizni [Sociology of life]. Moscow, UNITI-DANA Publ., 2016. 399 p.

22. Toshchenko Zh.T. Sotsiologiya zhizni kak teoreticheskaya kontseptsiya [Sociology of life as a theoretical concept]. Sotsiologicheskie issledovaniya, 2015, no. 1, pp. 106-116.

23. Chuprov V.I., Zubok Yu.A., Williams K. Molodezh v obshchestve riska [Youth in a risk society]. Moscow, Nauka Publ., 2001. 229 p.

Received: 24 April 2021. 